\title{
Velhice no meio urbano e rural
}

Me. Cezar Grontowski Ribeiro,

Dra. Fátima Ferretti (editora-chefe)

FisiSenectus. Unochapecó Ano 5, n. 1 - Jan/Jun. 2017 p. 1-2

O mundo está passando por um período de transição demográfica. Até pouco tempo, caracterizava-se por altos índices de natalidade e mortalidade, sendo que, atualmente, as taxas de fecundidade apresentam valores decrescentes enquanto a expectativa de vida aumenta, com consequente elevação da proporção de idosos em relação ao número de jovens. Tanto o meio rural quanto o urbano têm sofrido inúmeras transformações que impactam diretamente na vida daqueles que ali residem. No Brasil, o IBGE - Instituto Brasileiro de Geografia e Estatística ${ }^{1}$ demonstra em seus dados que houve um incremento de $0,7 \%$ dos idosos que vivem em ambiente rural e $4,28 \%$ dos que habitam zonas urbanas, quando analisado o período de 2000 a 2010.

Atualmente meio rural e urbano são abordados na perspectiva de continuum, em que se entende haver uma aproximação de ambos os contextos, derivados tanto da modernização do rural - que acaba com a visão de atraso -, quanto da variabilidade do urbano - que extingue a noção de que morar na cidade remete a progresso, dando lugar a uma multidimensionalidade em que se percebem potencialidades e dificuldades para se viver em ambos os contextos. Dessa maneira, municípios menores assumem mais características rurais, voltados à produção de alimentos, principalmente, enquanto que cidades de médio e grande porte apresentam um perfil urbano pautado no desenvolvimento de tecnologia e informação ${ }^{2}$. O IBGE tem considerado como rural todo município com menos de 25.000 habitantes. Se essa classificação for tomada como referência, cerca de $75 \%$ dos municípios brasileiros estariam enquadrados como rurais ${ }^{3}$.

De acordo com o IBGE ${ }^{1}$, o contingente populacional brasileiro é de 190.755.799 habitantes, sendo que destes $20.590 .597(10,79 \%$ ) possuem mais de 60 anos (3,9\% são homens que vivem em área urbana, 0,9\% são homens vivendo em área rural, 5,19\% são mulheres vivendo em área urbana e $0,81 \%$ são mulheres vivendo em área rural), com uma tendência de elevação desses percentuais até 2025, quando o país terá a sexta maior população de idosos do planeta, com os idosos representando cerca de $29 \%$ do total da população brasileira em 2050.

É importante destacar que existem diferenças de distribuição populacional dos idosos no Brasil quanto ao meio em que vivem, sendo que a proporcionalidade de homens e mulheres é diferente nos ambientes urbano e rural. Quando analisado o número total de idosos, existe predominância feminina no ambiente urbano (48,05\% contra 36,09\% de homens) enquanto que no rural há maior número de idosos do sexo masculino (8,38\% de homens e 7,48\% de mulheres), verificando-se, de maneira geral, que a proporção atual de idosos homens é de 81 para cada 100 mulheres $^{1}$.

No que se refere à manutenção da saúde o que está em jogo para o idoso é sua autonomia e independência, ou seja,

$$
\text { Fisiß̌enectus }
$$


a capacidade de determinar e executar seus próprios desígnios. Ramos ${ }^{4}$ explica que:

[...] qualquer pessoa que chegue aos oitenta anos capaz de gerir sua própria vida e determinar quando, onde e como se darão suas atividades de lazer, convívio social e trabalho (produção em algum nível), certamente será considerada uma pessoa saudável, independentemente do número de enfermidades crônicas que tenha. ${ }^{4}$

0 meio rural, segundo estudos, apresenta meIhores condições para o envelhecimento nos níveis familiar, psicológico e social ${ }^{5,6}$. Foram evidenciadas como vantagens de viver em meio rural: - o fato do contexto físico permanecer estável por um período mais duradouro, onde as transformações são graduais e mais lentas, criando um sentimento de pertencimento do indivíduo em relação ao meio; maior estabilidade da população, o que reflete na criação e manutenção de laços afetivos com parentes e vizinhos, obtendo maior apoio prático, emocional e psicológico. 0 mesmo não é verificado, de acordo com os autores, nos ambientes urbanos, onde a agitação e o ritmo de vida diminuem a possibilidade de usufruir desses aspectos em sua plenitude. 0 maior benefício de residir no ambiente rural, entretanto, é

\section{o sentido de identidade ${ }^{7,8}$.}

Já outras pesquisas apontam que viver em meio urbano proporciona maiores vantagens em relação ao rural no que se refere aos aspectos físicos e psicológicos, e nas questões de acesso à informação e serviços de saúde ${ }^{9,10}$.

“O prolongamento da vida é uma aspiração de qualquer sociedade, este somente pode ser considerado como uma real conquista na medida em que se agregue qualidade aos anos adicionais de vida"11. Esse pensamento remete à necessidade de realizar estudos que possam fornecer subsídios para discussão de estratégias que permitam ao idoso permanecer ativo e independente, garantindo sua qualidade de vida. Se o nível de independência é importante para garantir uma boa condição de saúde, manter-se ativo passa a ser necessário, e estudar esse tema passa a ser fundamental para identificar informações que permitam estabelecer ações e estratégias para garantir a independência funcional dessa população, independente do meio em que residam.

\section{Referências}

$\infty<\infty<\infty<\infty<\infty<\infty<\infty<\infty<\infty<\infty<\infty<\infty<\infty<\infty<\infty<\infty<$

1. Instituto Brasileiro de Geografia e Estatística. Diretoria de Pesquisas. Síntese de Indicadores Sociais. Rio de Janeiro: IBGE; 2010.

2. Lindner M, Alves FD, Ferreira ER. Presença da ruralidade em municípios gaúchos: o exemplo de Silveira Martins, RS. In: XIX Encontro Nacional de Geografia Agrária. São Paulo; 2009. p. 1-15.

3. Martins CR, Albuquerque FJB de, Gouveia CNNA, Rodrigues CFF, Neves MT de S. Avaliação da qualidade de vida subjetiva dos idosos: uma comparação entre os residentes em cidades rurais e urbanas. Estud. interdiscip. envelhec. 2007;11:135-54.

4. Ramos LR. Fatores determinantes do envelhecimento saudável em idosos residentes em centro urbano: Projeto Epidoso, São Paulo. Cad. saúde pública. 2003;19(3):793-798.

5. Dal Pizzol T da S, Pons E da S, Hugo FN, Bozzetti MC, Sousa M da LR de, Hilgert JB. Uso de medicamentos entre idosos residentes em áreas urbanas e rurais de município no Sul do Brasil: um estudo de base populacional. Cad. saúde pública. 2012;28(1):104-114.

6. Márquez-Montero G, Loret de Mola C, BernabéOrtiz A, Smeeth L, Gilman RH, Miranda JJ. Healthrelated quality of life among urban and rural to urban migrant populations in Lima, Peru. Rev. peru med. exp. salud pública. 2011;28(1):35-41.

7. Sequeira A, Silva MN. O bem estar da pessoa idosa no meio rural. Anál. psicol. 2002;20(3):505-16.

8. Bonomo M, Souza L de, Melotti G, Palmonari A. Princípios organizadores das representações de rural e cidade. Soc. estado. 2013;28(1):91-118.

9. Ayres KV, Brito SMO, Lipp MN. Stress feminino: um fenômeno possível na cidade e na roça. In: Fernandes A, Medeiros ILA, Brasileiro MCE. Olhar Multifacetado na Saúde. Campina Grande: EDUEP; 1999. p.145-171.

10. Hinck $S$. The lived experience of oldest-old rural adults. Qual. health res. 2004;14(6):779-791.

11. Veras R. Envelhecimento populacional contemporâneo: demandas, desafios e inovações. Rev. saúde pública. 2009;3(3):548-554. 